\title{
RELAÇÕES ENTRE CONCEPÇÕES E PRÁTICAS DE EDUCAÇÃO EM SAÚDE NA VISÃO DE UMA EQUIPE DE SAÚDE DA FAMÍLIA
}

\author{
RELATIONSHIPS BETWEEN EDUCATIONAL CONCEPTIONS AND PRACTICES IN HEALTH \\ IN THE VIEW ON A FAMILY HEALTH TEAM
}

Elisangela Pinafo ${ }^{1}$

Elisabete de Fátima Polo de Almeida Nunes ${ }^{2}$

Alberto Durán González ${ }^{3}$

Mara Lúcia Garanhani ${ }^{4}$

Resumo Este estudo objetiva analisar as concepções de educação em saúde de profissionais da equipe de Saúde da Família e pensar criticamente sobre a relação estabelecida entre as práticas de educação em saúde e os discursos desses trabalhadores. Trata-se de uma pesquisa qualitativa que adota a análise de discurso como referencial teórico e técnicas de observação e entrevistas para a produção dos dados. Os modelos curativos e de transmissão do conhecimento encontram-se fortemente arraigados na concepção e nas práticas de educação em saúde, prevalecendo uma relação vertical, impositiva, superior, na qual o profissional é o detentor do saber. Os trabalhadores sentemse educadores, e observa-se uma postura que considera o processo de trabalho educativo voltado para o aprendizado mútuo e o respeito aos conhecimentos prévios da população, porém essa percepção encontra-se presente somente em seu discurso, necessitando ser incorporada à sua prática para que haja a mudança nos serviços de saúde. Verificou-se a necessidade de maior valorização do papel do trabalhador como sujeito propulsor de mudanças na prática educativa e no modelo de atenção em saúde vigente, bem como a importância do reconhecimento do usuário como sujeito atuante na própria saúde e com capacidade de intervenção na sua realidade.

Palavras-chave educação em saúde; Saúde da Família; recursos humanos em saúde.

\begin{abstract}
This study aims to analyze the health education concepts among the professionals on the Family Health team and to think critically about the relationship between health education practices and these workers' discourses. It is a qualitative study that uses discourse analysis as its theoretical framework and observation techniques and interviews to produce its data. The models of healing and conveying knowledge are strongly rooted in the concept and practice of health education, in which a vertical, taxing, superior relationship prevails and under which the professional is the keeper of knowledge. The workers consider themselves as educators, and there is a posture among them that envisions the process of educational work aimed at mutual learning and respect for the population's prior knowledge; however, this perception is only in their discourse and should be incorporated into their practice in order for there to be a change in health services. There is a need for a greater appreciation not only of the role played by the worker as a subject who is a driver of change in the educational practice and in the health care model in force, but also of the importance of acknowledging the users as subjects acting in their own health and capable of intervening in their own reality.
\end{abstract}

Keywords health education; family health; human resources in health. 


\section{Introdução}

A educação se faz fortemente presente no cotidiano do setor saúde, sendo uma prática fundamental no contexto do Sistema Único de Saúde (SUS) do Brasil. O conceito de educação em saúde e suas práticas desenvolveram-se nas últimas décadas de forma significativa, reorientando as reflexões teóricas metodológicas neste campo de estudo (Gazinelli et al., 2005).

A educação na área da saúde pode ser vista como um campo de práticas que ocorre nas relações sociais estabelecidas pelos profissionais de saúde entre si, com a instituição e, sobretudo, com o usuário, no desenvolvimento cotidiano de suas atividades (L'Abatte, 1994).

Neste trabalho, a educação em saúde é entendida como um processo educativo de construção de conhecimentos em saúde que visa à apropriação temática pela população, tornando-se um conjunto de práticas do setor que contribui para aumentar a autonomia das pessoas no seu cuidado. Por fim, busca alcançar uma atenção de acordo com suas necessidades, como também potencializar o exercício do controle social sobre as políticas e os serviços de saúde para que estes respondam às necessidades da população (Brasil, 2008). Assim, a educação em saúde tem como objetivo promover na sociedade a inclusão social e a promoção da autonomia das populações na participação em saúde.

Essa concepção também se faz mais próxima da proposta pedagógica de Paulo Freire, que orienta um projeto pedagógico por ele denominado de educação popular, no qual se deve buscar uma educação que seja capaz de mudar a sociedade, favorecer o diálogo com teorias e práticas de um 'ouvir o outro' para educá-lo e para educar-se com ele, de levar em conta as representações dos sujeitos, sua trajetória de vida, experiências, saberes e culturas (Brandão, 2001).

A educação em saúde é, portanto, um recurso por meio do qual o conhecimento cientificamente produzido na área da saúde, intermediado pelos profissionais, tem a intenção de atingir a vida cotidiana das pessoas, uma vez que a compreensão dos condicionantes do processo saúde-doença oferece subsídios para a adoção de novos hábitos e condutas de saúde (Alves, 2005).

Vasconcelos (1999) destaca a atenção básica como um contexto privilegiado para o desenvolvimento dessas práticas, devido à sua maior proximidade com a população e à ênfase nas ações preventivas e promocionais.

O Ministério da Saúde aborda a educação em saúde como atribuição básica e essencial da equipe de Saúde da Família. Assim, essa prática é prevista e atribuída a todos os profissionais que compõem a equipe (Brasil, 2007).

A formação de profissionais aptos para trabalharem no modelo de saúde proposto pela Estratégia Saúde da Família (ESF) torna-se um desafio para o seguimento de uma assistência voltada à promoção da saúde. Assim, verifi- 
ca-se a necessidade de repensar as práticas educativas realizadas no contexto dessa estratégia (Gil, 2005).

Dessa forma, surgem as seguintes questões: qual a concepção de educação em saúde dos trabalhadores da ESF? Como esta concepção se revela na produção do cuidado na prática cotidiana?

Analisar as concepções de educação em saúde dos trabalhadores nos permite conhecer como esses profissionais se relacionam com os seus instrumentos de trabalho, possibilitando nos revelar o seu pensamento sobre a produção do cuidado com base no processo educativo em saúde. Em contrapartida, a análise de como se dá o processo educativo em saúde na sua prática cotidiana revela como as ações em saúde influenciam e modificam as concepções e percepções dos trabalhadores sobre a educação em saúde no contexto de sua prática.

Segundo Pereira (1993), o modo como as pessoas veem o mundo e o interpretam pode determinar a forma como agem dentro de sua realidade. No contexto da Atenção Básica, a forma como o profissional compreende a educação em saúde também pode determinar como ele a pratica.

Existem pesquisas, como a de Bornstein e Stotz (2009), que criaram uma tipologia para caracterizar as práticas de educação dos agentes comunitários de saúde, o que nos mostra a presença da mediação convencedora e da mediação transformadora. Para esses autores, embora o cotidiano do trabalho em saúde tenda a levar a prática educativa por meio da mediação devido ao modo aligeirado como são feitas essas atividades, em razão das numerosas atribuições que são conferidas aos agentes comunitários e também de sua situação na cadeia hierárquica dos serviços de saúde, existe uma compreensão de que sua prática é realizada de determinada forma. Porém, essa prática torna-se distorcida e distante de sua percepção voltada para a mediação transformadora em necessidade das mudanças nas práticas em saúde, entrando em conflito com o modo como o agente comunitário vê a educação em saúde e a forma como ele a pratica, revelando que o modelo de atenção à saúde e a maneira como o processo de trabalho está organizado podem influenciar nas práticas educativas.

Assim, este estudo teve como objetivo analisar as concepções de educação em saúde de profissionais da equipe de Saúde da Família e pensar criticamente sobre a relação estabelecida entre as práticas de educação em saúde e o discurso desses trabalhadores.

\section{Percurso metodológico}

Este artigo é parte de uma dissertação de mestrado, intitulada "Educação em saúde: o cotidiano da equipe de Saúde da Família", sendo um subprojeto 
que teve como propósito compreender a visão de profissionais de saúde sobre a prática da educação em saúde na estratégia Saúde da Família (PINAFO, 2010).

O presente estudo utiliza a abordagem qualitativa que, segundo Minayo e Deslandes (2002), busca a compreensão ou explicação em profundidade dos valores, práticas, lógicas de ação, hábitos e atitudes de grupos sobre a saúde.

Esta pesquisa foi realizada em Santa Mariana, um município de pequeno porte situado no norte do Paraná. A população estudada compreendeu os profissionais de saúde de duas equipes de Saúde da Família, que trabalham em diferentes unidades de saúde com áreas de abrangência distintas, sendo que uma das equipes atua na área rural do município.

Todos os profissionais das duas equipes foram entrevistados e suas práticas foram observadas, totalizando 14 trabalhadores. Dentre as categorias profissionais dos participantes, estão: enfermeiras, auxiliares de enfermagem, médicos e agentes comunitários.

Primeiramente realizou-se a observação das práticas educativas no cotidiano de trabalho da equipe de Saúde da Família, que consistiu no acompanhamento de atividades desenvolvidas pelos profissionais. A observação foi realizada pela primeira autora do presente artigo, no ambiente de trabalho de cada equipe em dias e períodos alternados durante três meses, de abril a junho de 2009. Quanto à observação, analisaram-se as atividades educativas realizadas pelos profissionais da equipe de Saúde da Família diante de situações apresentadas em seu cotidiano. Utilizou-se um diário de campo que auxiliou posteriormente na produção de um relatório minucioso das observações.

Logo após a fase de observação, foram realizadas entrevistas com os profissionais de saúde (mês de julho de 2009), gravadas e posteriormente transcritas. A entrevista foi conduzida com base em um roteiro que continha, na primeira parte, os dados de identificação e a experiência profissional com educação em saúde e, na segunda, os aspectos que contemplaram o tema abordado neste artigo, como a visão dos trabalhadores da equipe de Saúde da Família quanto às suas concepções sobre a educação em saúde e sua prática.

A análise dos dados deu-se pela metodologia de análise de discurso, tendo como embasamento teórico o referencial de Spink (2004), cujo foco central é o construcionismo social, mostrando ser um caminho para se entender a produção de sentidos no cotidiano. Para Spink (2004), o sentido é uma construção social, interativa e coletiva, por meio da qual as pessoas constroem os termos que compreendem e lidam com as situações e os fenômenos a sua volta.

Para fazer aflorar os sentidos neste estudo, procurou-se compreender o significado das falas dos entrevistados e do material produzido no período de observação por meio do desenvolvimento do mapa de associação de ideias, 
que se constituiu num instrumento de visualização e de organização dos assuntos discutidos e ajudou a dar subsídios ao processo de interpretação, facilitando a comunicação dos passos subjacentes ao processo interpretativo.

A construção desse mapa iniciou-se pela definição de categorias gerais, de natureza temática, que refletiram os objetivos do presente estudo. No primeiro momento, buscou-se organizar os conteúdos para preservar a sequência das falas, mantendo o diálogo intacto, sem fragmentação, sendo deslocado para as colunas previamente definidas. Em seguida, foram identificados os processos de interação mediante a esquematização visual da observação e das entrevistas como um todo.

Num segundo momento, fez-se a releitura do material do mapa de associação tomando-se as unidades de significados interpretadas. Em seguida, foram realizadas a aproximação e as convergências e divergências presentes. Essa aproximação, buscando as evidências entre as unidades de significado, possibilitou a construção de categorias que configuram a estrutura do fenômeno estudado.

Da análise das entrevistas e das observações, emergiram as seguintes categorias: Concepção sobre educação e a relação com suas práticas educativas; e Educação em saúde enquanto tecnologia de trabalho.

Os profissionais entrevistados foram identificados em seus depoimentos por meio de letras iniciais da sua profissão e por números (E1, M2, AE3, A4...), como forma de garantir o anonimato dos entrevistados. As falas serão apresentadas fazendo parte do texto, entre aspas, seguida da indicação do profissional que a pontuou.

Os princípios éticos que nortearam esta pesquisa - aprovada pelo Comitê de Ética em Pesquisa da Universidade Estadual de Londrina (UEL), Paraná, com o protocolo n. 181/08 - estão contemplados na resolução n. 196/96, que regulamenta a pesquisa envolvendo seres humanos (Brasil, 1996).

\section{Resultados e discussão}

\section{Caracterização dos sujeitos da pesquisa}

No total, foram 14 os participantes do estudo. Oito profissionais trabalhavam na unidade básica de saúde (UBS) da área urbana e seis na UBS da área rural, sendo 13 do sexo feminino. A faixa etária variou de 22 a 48 anos. Pertencem a distintas categorias profissionais, sendo duas enfermeiras, dois médicos, quatro auxiliares de enfermagem e seis agentes comunitários de saúde (ACS). As enfermeiras, os médicos e uma técnica de enfermagem tinham formação universitária - esta última com graduação em pedagogia; os demais profissionais apresentavam o Ensino Médio completo. Os auxiliares de 
enfermagem completaram o curso técnico, e os ACS realizaram a capacitação de agentes comunitários ofertada logo após sua contratação, no ano de 2006.

Todos os entrevistados eram concursados em emprego público para atuação na Saúde da Família, no regime de Consolidação das Leis do Trabalho (CLT), e foram contratados em 2006, tendo, portanto, três anos de atuação, com uma carga horária contratual de quarenta horas semanais.

O tempo de formação na área da saúde desses trabalhadores variou de três a 12 anos. A maioria apresentou experiência anterior de trabalho na Saúde da Família entre três e seis anos. Somente uma ACS e uma auxiliar de enfermagem não haviam trabalhado anteriormente na Saúde da Família.

Quanto aos profissionais de nível superior, as duas enfermeiras pesquisadas apresentavam especialização em Saúde da Família e haviam completado o curso recentemente; quanto aos médicos, um tinha especialização na área de ginecologia/obstetrícia e outro na área de geriatria.

Os profissionais entrevistados disseram ter experiência anterior no campo da educação em saúde, e esta foi adquirida no trabalho da Saúde da Família por meio do desenvolvimento de atividades em grupos e palestras educativas. As enfermeiras foram as profissionais que pontuaram desenvolver frequentemente atividades educativas, além de apresentarem experiência na docência, uma na área de enfermagem e outra na capacitação para ACS. Um dos médicos referiu ter ministrado aulas para pós-graduação em curso de enfermagem obstétrica.

Ao analisar a concepção de educação em saúde de profissionais da equipe de Saúde da Família e a relação das práticas educativas com os discursos desses trabalhadores, emergiram duas categorias: Concepção sobre educação e a relação com suas práticas educativas; Educação em saúde enquanto tecnologia de trabalho.

\section{Concepção sobre educação e a relação com suas práticas educativas}

Esta categoria sinaliza a relação do profissional de saúde com a sua prática educativa e a concepção de educação presente no seu exercício cotidiano.

Com base no discurso dos profissionais e na observação realizada, verificouse que a educação em saúde encontra-se presente no cotidiano de trabalho da equipe de Saúde da Família, sendo considerado que "toda ação desenvolvida com os pacientes e usuários" (AE2) tem um potencial educativo. O profissional entende seu trabalho como uma forma de educar o usuário, percebendo que "toda ação em saúde" (El) reflete uma conduta educativa. Essa ação educativa é compreendida como inerente à prática do cuidado: "Tudo tem que ser devidamente esclarecido; educação em saúde é você, além de cuidar da saúde, estar educando as pessoas para aquilo que você está aplicando" (E2). 
Refletindo a educação em saúde como parte integrante do processo de trabalho, Alves (2005) mostra que toda ação em saúde é considerada uma ação educativa, e no presente estudo os trabalhadores reconhecem essa condição. Da mesma forma, o Ministério da Saúde a aborda como uma atividade que "deve ser desenvolvida por todos os profissionais de saúde conforme definição de suas atribuições básicas" (Brasil, 1997, p. 15); assim, estes devem oportunizar seu contato com os usuários para abordar os aspectos preventivos e de educação sanitária.

A primeira condição para que um ser possa assumir um ato comprometido está em ser capaz de agir e refletir. Freire (1996) diz que é preciso que o educador seja capaz de, estando no mundo, saber-se nele. Refletindo os dizeres de Freire com o encontrado no presente estudo, entende-se que o trabalhador reconhece a importância da educação e se coloca nesse papel diante das situações vivenciadas, percebendo a educação em saúde nas suas atividades cotidianas: “Toda hora, de certa forma, está sendo feita educação em saúde. Tudo que é feito tem que explicar o que está fazendo, ou porque você está deixando de fazer" (E2).

O papel do profissional de saúde é descrito por vários autores. Dentre eles, Alves (2005) relata que os profissionais de saúde da Atenção Básica devem prestar uma atenção preventiva, curativa e reabilitadora, além de serem comunicadores e educadores em saúde. L'Abbate (1994) e Smeke e Oliveira (2001) compreendem que todo profissional de saúde é um educador em potencial, sendo condição essencial para sua prática o seu próprio reconhecimento como sujeito do processo educativo.

Ayres (2001) observa que o reconhecimento do profissional como sujeito está no centro de todas as propostas renovadoras identificadas no setor saúde, e como profissional, este é considerado em suas qualidades exercendo ações transformadoras que produzem história.

Os participantes referiram-se a "esta atividade" como parte integrante do seu processo de trabalho; no entanto, sinalizam que acabam "fazendo no dia a dia automaticamente" (E2). Esta conotação do trabalho educativo como automático apresenta uma ambiguidade em sua interpretação, podendo ele ser visto como um procedimento realizado rotineiramente com a intenção de implementar o cuidado, como também associado à reprodução de uma ação que o profissional está condicionado a fazer. De acordo com Campos (1998), o trabalho em saúde muitas vezes assume um caráter automático, de postura repetitiva, de reprodução, podendo associar-se ao trabalho mecânico visto no Fordismo. Assim, por um lado esse trabalho educativo pode ser realizado de forma repetida, semelhante para todas as pessoas, não tendo uma reflexão da individualidade de cada sujeito no processo educativo. Por outro lado, pode sinalizar a importância que os profissionais dão às práticas educativas, vendo-as como inseparáveis da prática do cuidado. 
Neste estudo, verifica-se que o próprio reconhecimento que o profissional tem de seu papel como educador em saúde impulsiona-o à prática educativa, indissociável e inerente à ação do cuidar em saúde. Para todos os sujeitos entrevistados, a prática educativa traz sentido para o seu trabalho; eles dizem que "sem o ensinamento, sem a educação em saúde, sem a orientação, a saúde não vai para a frente" (M1).

Spink (2004) afirma que o homem só apreende os objetos à sua frente mediante o significado que esses objetos representam para ele. Smeke e Oliveira (2001) descrevem o fenômeno educativo como um processo contínuo e potencializador do aprendizado de cada momento. Mas os profissionais só apreendem o seu significado a partir do momento em que essa atividade traz sentido para o seu trabalho; assim, eles conseguem se ver como educadores, responsáveis e comprometidos com o propósito de melhorar a sua prática, além de percebêla como um processo contínuo que exige esforço e deve ser sempre estimulado.

Embora o trabalhador apreenda o significado da prática educativa a partir do momento em que esta traz sentido para suas ações, também vale a pena pensar que as demandas do processo de trabalho em saúde podem levar esse profissional a ter certa postura educativa, devido ao modo como o serviço está organizado, que o leva a reproduzir a lógica de controle dos serviços sobre a população implícita nas mediações convencedoras citadas por Bornstein e Stotz (2009). Segundo essas mediações, o trabalhador procura convencer a população com relação ao valor do saber tecnocientífico, não levando em consideração a existência da mediação transformadora, com o compartilhamento do conhecimento e maior permeabilidade dos serviços quanto às necessidades e demandas da população.

Os trabalhadores destacam a importância de o profissional "orientar as pessoas, abrindo os olhos delas" (A4). Freire (1996) afirma fazer parte da tarefa do educador não apenas ensinar os conteúdos, mas também ensinar a pensar certo, que consiste na ideia de aprofundar conhecimentos de prática, procurar descobrir e entender o que está escondido nas coisas, propiciando ao educando condições de superar o saber do senso comum. Dessa forma, o profissional de saúde se vê como condutor do processo educativo e entende que a "educação em saúde é seu dever" (A4), percebendo-se como sujeito "importante" (AE2) para a realização dessa ação.

Este mesmo achado foi apresentado por Melo, Santos e Trezza (2005) em estudo com dez profissionais de saúde, cujo objetivo foi verificar o entendimento desses trabalhadores sobre a educação em saúde, mostrando que todos os sujeitos entrevistados afirmaram ter o compromisso ou o dever de executar ações de educação em saúde. Alegam ser um compromisso profissional inerente a sua formação acadêmica, ou um princípio do Sistema Único de Saúde (SUS). Mencionam ainda os princípios do Programa Saúde da Família (PSF) como estratégia transformadora. 
No entanto, na presente pesquisa observaram-se as dificuldades de alguns profissionais em realizar as práticas educativas devido às suas limitações pessoais. Eles referiram-se à necessidade de se prepararem para assim exercerem a tarefa de educadores: "A educação depende muito da sua própria educação. Se você tem uma boa formação, você vai conseguir fazer uma boa educação em saúde, senão é complicado. Um estudo leva a outro estudo, não tem jeito" (Ml).

No estudo realizado por Wendhausen e Saupe (2003), cujo objetivo foi o de analisar a concepção de educação em saúde de profissionais da equipe de Saúde da Família, verificou-se que a prática educativa está fortemente ligada à capacitação continuada da equipe de saúde, bem como à educação formal dos trabalhadores.

A graduação em saúde, para Carvalho e Ceccim (2006), não tem tido uma orientação integradora entre ensino e trabalho. A integração entre o aprender e o ensinar no cotidiano de trabalho, segundo Feuerwerker (2005), revela a Educação Permanente em Saúde (EPS) como um dispositivo adequado para a mudança das práticas em saúde.

No presente estudo, analisamos a importância da formação e da atualização dos profissionais e a EPS como suporte para a sustentação das práticas educativas, garantindo assim o conhecimento necessário para a sua concretização.

A fragilidade nesses processos faz com que aconteça uma situação ambígua, pois ao mesmo tempo em que eles se sentem educadores e valorizam o espaço como troca de experiências ainda concebem a educação em saúde como um processo de transmissão de conhecimento, no qual o profissional “sempre está passando alguma coisa para o paciente (AEl). Considera-se detentor de um saber que precisa aproveitar para estar passando algumas informações" (El).

A concepção de educação em saúde como transmissão de informações está fortemente presente na prática cotidiana dos profissionais observados, sendo essa conduta predominante para a maioria dos trabalhadores. Em geral, os profissionais descrevem a prática da educação em saúde como o ato de passar, repassar, informar, orientar e transmitir conhecimento ao paciente (Besen et al., 2007; Wendhausen e Saupe, 2003; Silva, Rotenberg e Vianna, 2004; Rios e Vieira, 2007).

O modelo de educação focado na transmissão de informações prevê a ação educativa como um repassar de conhecimentos ao outro, e o educador é aquele que sabe e que deve dizer algo, enquanto o educando não possui conhecimentos e deve recebê-los passivamente (Freire, 1996). Este mesmo autor afirma que quando se realiza a educação como um processo de depósito de ensinamentos, considera-se o educando como uma caixa vazia. Educa-se para arquivar o que se deposita; isto forma uma consciência bancária. Segundo Vasconcelos (1999), a educação em saúde como transmissão de 
informações traduz-se por levar até a população a compreensão e as soluções consideradas corretas pelos profissionais, não valorizando as diferentes formas de apreensão do conhecimento e a possibilidade de recriá-lo de acordo com os valores, crenças e cultura de cada indivíduo ou grupo.

Para Freire (1997) e Gadotti (1983), a educação é uma forma de intervir no mundo, e esta intervenção pode ser sentida tanto na reprodução da ideologia dominante como pelo caráter de desvendá-la. A concepção de educação em saúde calcada na reprodução da ideologia dominante pode ser vista na educação como transmissão, pois muitas vezes o profissional procura impor um conhecimento que julga correto para ser seguido. Já quando a educação em saúde leva em consideração os valores, crenças e visão de mundo do indivíduo, ela tem o caráter de desvendar a ideologia dominante, buscando uma ação próxima da realidade do usuário.

De acordo com Freire (1997), a ideologia hegemônica tem a capacidade de mascarar a realidade, fazendo com que os sujeitos aceitem o discurso fatalista. Freire diz que é preciso reconhecer que o homem é um ser condicionado, mas capaz de superar tal condicionamento que reduz a presença do homem em sua história e no seu ambiente social a uma pura adaptação (Freire, 1997).

Segundo relato dos trabalhadores e com base na observação realizada, os profissionais que apresentaram uma concepção de educação em saúde calcada na transmissão de conhecimentos demonstraram em sua atitude de educar uma posição superior à dos usuários, prevalecendo uma relação vertical, impositiva, na qual o profissional é o detentor do saber, enquanto o saber do usuário não é valorizado: "As pessoas não têm tanta informação, a maioria não é alfabetizada, não tem leitura, não tem conhecimento de muitas coisas" (A6).

Conforme Besen et al. (2007), essa postura do profissional é reflexo de sua formação hospitalocêntrica, biologicista e fragmentada, centrada no modelo flexneriano, que utiliza uma metodologia de ensino vertical e não problematizadora.

Com base nesse tipo de postura, também apresentada pelos profissionais estudados, Vasconcelos (1999) sinaliza que é preciso valorizar o conhecimento popular para assim romper com a verticalidade da relação profissional-usuário, presente nas práticas educativas autoritárias. De acordo com Valla (1996, p. 179), o trabalhador oferece seu saber entendendo que o saber "da população é insuficiente e, por esta razão, inferior, quando na realidade, é apenas diferente". Isto demonstra a dificuldade de o profissional admitir que os grupos populares sejam produtores de conhecimento e, por esse motivo, assumam o papel de tutores na relação com esses grupos.

Ao se refletir sobre os dizeres desses autores e com a observação da prática educativa, pôde-se perceber a necessidade de o profissional deixar 
de se sentir o detentor do conhecimento que julga correto e que deve ser seguido pelo usuário, para que esse trabalhador valorize as diferentes formas de apreensão do conhecimento, no intuito de quebrar a hegemonia de seu saber técnico-científico como soberano em relação ao conhecimento do usuário, para assim se aproximar da realidade desse usuário e reconhecer que este é capaz de superar o seu conhecimento de senso comum. De acordo com Brandão (1981), esses saberes são passados de geração em geração por meio de crenças, valores, formas de representação do mundo, lógicas, códigos, formas próprias de saber: “Assim, as formas próprias de educação do povo servem a ele como redes de resistência a uma plena invasão da educação e do saber de fora da classe" (Brandão, 1981, p. 105).

É preciso que o profissional valorize o saber popular para assim compreender o processo educativo como um espaço de troca de saberes e valorização do indivíduo, e também que ele reconheça o usuário como sujeito atuante na própria saúde e com capacidade de intervenção na sua realidade, para assim construir a história e a trajetória da saúde nos serviços de atenção básica vigentes.

\section{Educação em saúde como tecnologia de trabalho}

Esta categoria vem nos trazer a concepção da educação em saúde como tecnologia para o desenvolvimento no cuidado preventivo e propulsora de mudanças na Atenção Básica.

Conforme já mencionado, a educação em saúde encontra-se presente no processo de trabalho, sendo uma prática inerente ao cuidado em saúde. De acordo com Merhy e Onocko (1997), o trabalho em saúde se refere a um mundo próprio, complexo, diverso, criativo, dinâmico, em que cotidianamente usuários se apresentam portadores de algum problema de saúde e buscam, juntamente com os trabalhadores que ali estão, resolvê-los.

Mehry (2003), ao descrever a produção do cuidado, estabeleceu três categorias para tecnologias de trabalho em saúde. Chamou de 'tecnologias duras' as que estão escritas nas máquinas e nos instrumentos e têm esse nome porque já estão programadas a priori para a produção de certos produtos; de 'leve-duras' as que se referem ao conhecimento técnico, por ter uma parte dura que é a técnica, definida anteriormente, e uma leve, que é o modo próprio como o trabalhador a aplica, podendo assumir formas diferentes dependendo sempre de como cada um trabalha e cuida do usuário; e 'tecnologias leves', que dizem respeito às relações que, de acordo com o autor, são fundamentais para a produção do cuidado e se referem a um jeito ou atitude próprio do profissional que é guiado por uma certa intencionalidade vinculada ao campo cuidador, ao seu modo de ser, à sua subjetividade. 
São tecnologias, também, porque dizem respeito a um saber, isto é, competências para os trabalhadores de saúde lidarem com os aspectos relacionais que envolvem os atos produtivos.

De acordo com a produção do cuidado em saúde, a educação em saúde pode ser vista como uma tecnologia leve em razão de sua prática estar diretamente ligada às relações estabelecidas entre trabalhador e usuário, às suas intencionalidades, subjetividades, saberes, enfim, num campo de competências e atitudes profissionais em que está vinculada a um jeito próprio de se produzirem os processos de cuidar em saúde.

A educação em saúde como tecnologia de trabalho é aplicada na prática do cuidado por meio de ações educativas desenvolvidas no cotidiano da Atenção Básica. Para a compreensão dessas práticas, faz-se necessário relacioná-las com a concepção de educação em saúde por parte de quem a realiza. Na presente pesquisa, a concepção do fazer educação em saúde está fortemente arraigada no fazer a prevenção de doenças por meio de práticas educativas, pois para o profissional “a educação em saúde é você estar fazendo a prevenção" (A4). Os profissionais demonstraram que a "melhor maneira" de se trabalhar com o tema 'saúde' é por meio da "prevenção, e isso só se consegue fazendo a educação em saúde, não só no atendimento básico. Se não fizer a prevenção, só vai aumentar o número de doenças sem conseguir o seu controle" (Ml), destacando-se que as práticas educativas são como um caminho que leva à melhora dos índices de saúde da população, portanto uma tecnologia de trabalho que produz bons resultados.

No estudo realizado por Besen et al. (2007) com o objetivo de investigar a compreensão da educação em saúde de dentistas, enfermeiros e médicos da equipe de Saúde da Família, igualmente ao encontrado no presente estudo, foi verificado que os discursos dos entrevistados são permeados por orientações preventivas, que se fazem presentes nas ações pedagógicas de forma pontual e focalizadas nas especificidades de cada intervenção.

Refletindo essa concepção presente na prática educativa dos profissionais estudados, Luckesi (1994) entende que os sentidos da educação na sociedade são expressos pelos conceitos de educação como redenção, reprodução e como um meio de transformação da sociedade.

Essa postura de educar com a intenção de prevenir está, muitas vezes, ligada à educação como reprodução da sociedade. O conceito de educação como reprodução da sociedade afirma que a educação faz parte da sociedade e a reproduz; dessa forma, busca entendê-la como elemento da própria sociedade, determinada por seus condicionantes e a serviço desta (Luckesi, 1994).

Para este autor, a educação reprodutora está relacionada à reprodução da força de trabalho, no sentido de garantir a produtividade da sociedade capitalista, oferecendo conhecimentos técnicos e determinando o comportamento dos sujeitos: “A reprodução da força de trabalho está ligada à submissão 
desta à ideologia dominante" (Luckesi, 1994, p. 44). Assim, podemos verificar que a sociedade espera que os indivíduos, força de trabalho do sistema capitalista, estejam saudáveis, isentos de qualquer comorbidade, para estarem ativos no processo de produção; dessa maneira, ela age oferecendo/impondo o conhecimento e comportamentos ditos saudáveis, que vão ao encontro da prevenção de patologias, visando que as pessoas sigam suas determinações. Essa manifestação se reflete no processo educativo em saúde, principalmente nas ações de prevenção, cujo foco encontra-se no seguimento de orientações que evitem ou distanciem os usuários de patologias que possam prejudicar o corpo humano, consequentemente, a sua força de trabalho objeto da produção capitalista.

Refletindo a educação como instrumento determinante da reprodução da ideologia dominante, na fala dos sujeitos pesquisados foi identificada uma postura educativa focada na cura de doenças, ou seja: educar em saúde "é explicar" para o usuário "sobre a doença, sobre os sintomas, sobre como é a prevenção e o tratamento" (AEl), referindo-se a um modelo de atenção preventivo, com enfoque no atendimento a determinada doença ou agravo à saúde. Da mesma forma, foi observado em todas as categorias profissionais o atendimento centrado na patologia do usuário, isto é: ao atender o paciente, muitas vezes o profissional focou sua atenção no problema de saúde trazido pelo usuário, procurando dar explicações, informações sobre a patologia, enfocando suas orientações nos exames clínicos e laboratoriais, medicações e encaminhamento a especialistas.

O modelo biológico do adoecimento está fortemente presente nas ações educativas desenvolvidas pela equipe de Saúde da Família. Segundo Laplantine (1991), esse modelo de pensar a educação em saúde tem sempre um agente externo causador da doença e que deve ser combatido. De acordo com Buss (2009), o foco de atenção se torna a patologia específica do paciente, não levando em consideração o indivíduo como sujeito ativo no seu processo saúde-doença; agindo-se dessa forma, pode-se ver que o profissional muitas vezes leva o processo educativo como um meio de intervir no processo saúde-doença, porém este se dá somente na explicação da patologia apresentada pelo paciente, deixando-se de lado a perspectiva de processo para reduzir a saúde à ausência de doença. Isso também pode estar relacionado ao fato de o modelo de saúde atual estar fortemente centrado em ações de cura, e também ao fato de a sociedade exigir de certa forma que o setor saúde, por meio dos trabalhadores, dê conta por completo dessa questão.

Quando a educação em saúde toma esse caráter reprodutivo, tende a levar a reflexão das práticas educativas como tecnologia leve-dura que está ligada a um conhecimento técnico, voltado para a imposição de um saber que auxilia no combate das patologias existentes que podem prejudicar o indivíduo e afastá-lo do processo educativo, em detrimento da imposição de 
um conhecimento do trabalhador, que o aplica nas relações de cuidado para com o usuário. Dessa forma, verifica-se que quando a prática da educação em saúde tende a ser realizada somente como tecnologia leve-dura, tende a distanciar o trabalhador do usuário e levar a um não reconhecimento deste indivíduo como centro do processo de trabalho em saúde, sujeito de valores e práticas responsáveis pela sua realidade.

O trabalho educativo é uma atividade que tem sempre uma finalidade para que se realize, a qual muitas vezes está ligada ao atendimento a determinada necessidade da pessoa, seja ela de que tipo for. No caso da saúde, Merhy (2003), utilizando a classificação de Cecílio (2001), sugere que as necessidades estão organizadas em cinco grandes grupos: o primeiro diz respeito à necessidade de boas condições de vida; o segundo conjunto fala da necessidade de se ser alguém singular com direito à diferença; o terceiro diz respeito à garantia de acesso a todas as tecnologias que melhorem e prolonguem a vida; um quarto, à necessidade de se ser acolhido e ter vínculo com um profissional ou equipe (sujeitos em relação); e o último fala da necessidade de autonomia e autocuidado na escolha do modo de 'andar a vida' (construção do sujeito).

Tendo em vista as necessidades de saúde, podemos verificar que a educação em saúde como tecnologia do cuidado permeia todas as necessidades de saúde apontadas por Cecílio. Dessa forma, o processo de trabalho educativo se revela como um caminho a ser percorrido, uma tecnologia de trabalho, uma ferramenta que deve ser utilizada para auxiliar os profissionais e o serviço de saúde a darem respostas às necessidades apresentadas pelos usuários, em busca de melhora nas condições de vida da população, que deve ter como objetivo maior o estímulo ao autocuidado, caminhando em direção à construção de sujeitos autônomos.

Essa construção de sujeitos autônomos vai ao encontro do sentido da educação como transformadora da sociedade, que faz parte da tendência pedagógica progressista libertadora e traz as ideias de Paulo Freire apontando a valorização da ação pedagógica inserida no contexto social, em busca de uma educação no sentido de transformação da realidade (Luckesi, 1994).

Segundo Morin (2006), a educação deve contribuir para formar cidadãos e despertar virtudes de solidariedade e responsabilidade, devendo ser entendida não apenas como um meio de adquirir conhecimentos, mas também de transformar a realidade do sujeito que é educado.

Como pressuposto de uma transformação na realidade de vida dos sujeitos que utilizam os serviços de saúde, publicações do Ministério da Saúde (Brasil, 1997) apontam o Programa Saúde da Família (PSF) como estratégia política que tem a intenção de oferecer uma atuação centrada nos princípios da vigilância em saúde, que para Mendes (1996) significa uma assistência integral, abrangendo todas as dimensões do processo saúde-doença. 
Com esse intuito, a integralidade é tomada como princípio de organização do processo de trabalho nos serviços de saúde, sendo caracterizada por Mattos e Pinheiro (2001, p. 57) “pela busca contínua de ampliar as possibilidades de apreensão das necessidades de saúde de um grupo populacional", dando prioridade às atividades preventivas e de promoção da saúde, sem prejuízo dos serviços assistenciais.

Na fala dos sujeitos pesquisados, existe um discurso de que a "educação em saúde é você estar fazendo a prevenção, pois a parte curativa, não adianta: tem que promover a saúde pra você ajudar um pouco" (A4). Segundo os entrevistados, esse modelo não produz resultados satisfatórios, havendo a necessidade de mudança no modelo de atenção. Eles identificam a promoção da saúde como um caminho ou forma de conduzir as práticas educativas nos serviços de saúde em busca de uma atenção à saúde mais adequada, porém nota-se que existe simultaneamente uma redução da promoção à prevenção, em que o enfoque maior nas práticas educativas é dado às práticas de prevenção de agravos.

Alves (2005) afirma que educar para a saúde implica ir além da assistência curativa; significa dar prioridade a intervenções preventivas e promocionais, expressando a assimilação do princípio da integralidade.

As intervenções de promoção da saúde propõem abordagens de fora do setor saúde, ou seja, abordagens que fortaleçam a busca de modificações das condições de vida, para que sejam dignas e adequadas; apontam para a transformação dos processos individuais de tomada de decisão para que levem à qualidade de vida e à saúde, e orientam-se ao conjunto de ações e decisões coletivas que possam favorecer a saúde e o bem-estar da população (Cerqueira, 1997).

No mesmo estudo realizado por Besen et al. (2007) citado anteriormente, chama-nos a atenção o fato de que, igualmente ao presente estudo, poucos profissionais de saúde realizam ações de promoção da saúde. Na abordagem educativa centrada na promoção da saúde, esta é entendida de forma ampliada, em que as pessoas são vistas em sua autonomia e em seu contexto político e cultural como sujeitos capazes de conduzir o seu modo de vida de forma saudável (Buss, 2009).

Essa visão do trabalhador, que busca fortemente a prevenção de doenças à promoção da saúde, pode estar atrelada ao fato de a promoção da saúde ser uma prática que despende recursos de vários setores além do setor saúde. Entendida em sua dimensão mais ampla, a operacionalização na busca da promoção da saúde torna-se mais complexa devido ao fato de o processo saúde-doença estar relacionado aos fatores socioeconômicos e culturais, entre outros, e à prática em saúde estar focada no modelo assistencialista, além de os usuários exigirem essa postura dos profissionais e do serviço de saúde. Mas também podemos refletir sobre o fato de que a prática educativa 
voltada para a promoção da saúde está em consonância com a tendência libertadora do modelo de educação, pois ambos reconhecem o contexto de vida dos indivíduos e buscam como finalidade potencializar a capacidade de conduzir a vida de forma saudável em direção à autonomia e ao estímulo ao autocuidado. No entanto, embora a visão predominante de educação em saúde seja a "transmissão de conhecimento à população" (AE3) e as atividades educativas estejam centradas na "prevenção de doenças" (A4), há por parte de alguns trabalhadores o discurso de buscar outra relação educativa como "ensinar" a população "a ter consciência, conscientizar de como a saúde é importante, para ter uma vida saudável" (A3).

O trabalhador refere-se ao fato de que ele "consegue mudar um pouco a visão de mundo do usuário, que o posto não funciona só para médico, só para doença, só para remédio, mas também funciona para você conseguir trabalhar melhor com a sua família" (AEl). Conforme os relatos descritos, o trabalhador vê nas práticas educativas uma tecnologia de trabalho que possibilita a oportunidade de incentivar a população a promover o seu autocuidado, a ser sujeito ativo. Para isso, procura contribuir para a compreensão e a conscientização sobre a dimensão da assistência integral à saúde da população.

A conscientização e a mudança são temas amplamente discutidos por Paulo Freire. A mudança de uma sociedade de oprimidos para uma sociedade de iguais e o papel da educação e da conscientização nesse processo de mudança são a preocupação básica desse autor. Com base nas informações coletadas por esta pesquisa, percebe-se um discurso propulsor de mudanças por parte de alguns profissionais de saúde, que se referem ao processo educativo para a conscientização do usuário, conscientização esta que envolve a visão de mundo desse sujeito.

Nessa visão mais progressista de educação em saúde, os profissionais referem que "acabam aprendendo com os usuários coisas da própria realidade deles, que os influenciam na forma de agir, na conduta dentro da UBS (E1); percebem essa relação como uma troca de saberes, eles aprendem com a gente e a gente aprende com eles" (A3), sendo pontuada como um caminho para a aprendizagem mútua, ou seja, tanto o profissional quanto o usuário ensinam e ambos aprendem.

O mesmo foi observado na conduta educativa das enfermeiras durante a realização de grupos educativos e no atendimento preventivo do câncer do colo uterino, que procuraram saber primeiramente o conhecimento do paciente sobre o assunto abordado para assim iniciar a sua prática educativa, embasada no conhecimento prévio dele, prosseguindo com explicações mais próximas da realidade do paciente. Dessa forma, o profissional aprende com o usuário e torna-se mais próximo do saber popular, que proporcionará melhor conduta educativa. 
Resultados similares ao encontrado nesta pesquisa foram descritos por Silva, Rotenberg e Vianna (2004) em estudo sobre a concepção de educação em saúde na ótica dos profissionais de saúde que atuam em grupos educativos, realizado com sete profissionais de saúde, no qual verificaram que os profissionais entenderam a educação como um processo, valorizando questões como o diálogo, a reflexão, a troca de saberes e o respeito.

Para Vasconcelos (1997), educar para a saúde requer que o profissional de saúde ajude o usuário a buscar a compreensão de seus problemas e de suas soluções, com base no diálogo e na troca de saberes, portanto, uma interação entre o saber científico e o popular, em que ambos ensinam e aprendem ao mesmo tempo.

Ao se refletir sobre os dizeres de Vasconcelos (1997) e os resultados da presente pesquisa, constatou-se a educação em saúde como um processo de interação, de relação com as diversidades dos sujeitos envolvidos na prática educativa. Com esse intuito, pode-se verificar implícita a intenção da educação em saúde como uma tecnologia que instiga conhecimentos expressos como os das tecnologias leves, presentes nos saberes e nas relações entre profissional de saúde e usuário dos serviços de saúde - tecnologia esta capaz de se tornar ferramenta imprescindível no trabalho em saúde e compromisso com a transformação das práticas em saúde, para o fortalecimento do sistema de saúde.

\section{Tecendo algumas considerações}

Neste estudo, a concepção de educação em saúde presente no discurso e nas práticas dos profissionais da equipe de Saúde da Família encontra-se fortemente embasada no modelo de transmissão do conhecimento e no modelo curativo de assistência à saúde. Tal concepção encontra-se vinculada à noção de prevenção de doenças e passagem de informação para a população, na qual a tarefa de ensinar e orientar está presente no discurso e na prática desses profissionais, sobressaindo o saber profissional sobre o conhecimento popular, na tentativa da mudança de comportamento e hábitos de vida da população.

Mesmo tendo fortes influências das práticas hegemônicas na concepção de educação em saúde apresentada pelos trabalhadores, constatou-se, por parte de alguns profissionais, uma postura que considera o processo de trabalho educativo voltado para o aprendizado mútuo e o respeito aos conhecimentos prévios da população. Porém, essa percepção encontra-se presente somente em seu discurso, necessitando ser incorporada à sua prática profissional para que haja a mudança nos serviços de Atenção Básica.

É necessário valorizar o papel do trabalhador como sujeito propulsor do processo educativo e suas conquistas no âmbito de suas práticas educativas 
cotidianas, para que esse profissional identifique em si mesmo sua potencialidade no campo da educação em saúde e seja incentivado para esse trabalho em busca da mudança do modelo de atenção para um modelo de saúde mais integral e igualitário.

A formação dos profissionais de saúde é uma problemática constatada, pois eles demonstraram não estar preparados para o trabalho educativo conforme a lógica do SUS. Por essa razão, existe a necessidade de readequações nas graduações dos cursos da área da saúde, principalmente incluindo de forma mais articulada a reflexão e o debate sobre o trabalho educativo desses profissionais durante sua formação. Para isso, é necessária também uma reflexão por parte dos profissionais formadores em saúde. Outro fator relevante diz respeito à EPS, visando aproximar a prática da educação em saúde com a realidade e a necessidade da nossa população.

Pôde-se refletir que quando a educação em saúde é vista como uma ação que valoriza as práticas de saúde hegemônicas pautadas na transmissão de conhecimentos tecnocientíficos para a cura de doenças, ela encontra forte influência das tecnologias leve-duras que preconizam o saber técnico, que pode estar voltado para o controle da população. No entanto, quando a prática educativa se embasa no conhecimento prévio e na realidade da população, entendendo-a como um processo, valorizando questões como o diálogo, a reflexão, a troca de saberes e o respeito, verifica-se fortemente a educação em saúde como tecnologia leve e ferramenta potencial de transformação nas relações de trabalho e na realidade do sistema de saúde.

Verifica-se a necessidade de valorização do indivíduo e do saber popular para que o processo educativo seja compreendido como um espaço de troca de conhecimentos, e também o reconhecimento do usuário como sujeito atuante da própria saúde, com capacidade de intervenção em sua realidade, para assim construir mudanças na história e na trajetória da saúde nos serviços de Atenção Básica vigentes.

Faz-se necessário fortalecer a participação social e a autonomia dos usuários, com isso contribuindo para a constituição de sujeitos sociais competentes e responsáveis por transformações sociais e políticas voltadas para o interesse da população e para a melhoria do modelo de atenção em saúde proposto pelo SUS.

Assim, temos que ter em mente que os programas de educação em saúde não devem se limitar a iniciativas que visem informar a população sobre os problemas de saúde. Devem ir além do campo da informação, considerando os valores, costumes e modelos sociais que levam a condutas e práticas educativas libertadoras, em que profissional e usuário são vistos como sujeitos, com papéis significativos, capazes de promover mudanças na realidade enfrentada por ambos e no modelo de saúde atual. 


\section{Colaboradores}

Elisangela Pinafo e Elisabete de Fátima P. A. Nunes trabalharam em conjunto no desenvolvimento desta pesquisa e em todas as etapas de produção do manuscrito. Alberto Durán González e Mara Lúcia Garanhani participaram na elaboração deste artigo.

\section{Notas}

1 Professora da Universidade Estadual do Norte do Paraná, Bandeirantes, Paraná, Brasil. Mestre em Saúde Coletiva pela Universidade Estadual de Londrina. <elisangelapinafo@ yahoo.com.br>

Correspondência: Rua Castro Alves, 518, CEP 86358-000, Panema, Santa Mariana, Paraná.

2 Professora do Departamento de Saúde Coletiva e do Programa de Pós-Graduação em Saúde Coletiva da Universidade Estadual de Londrina, Paraná, Brasil. Doutora em Saúde Coletiva pela Universidade Estadual de Campinas.<alnunes@sercomtel.com.br>

3 Doutorando em Saúde Coletiva pelo Programa de Pós-Graduação em Saúde Coletiva da Universidade Estadual de Londrina, Paraná. < betoduran80@gmail.com>

4 Professora do Departamento de Enfermagem e do Programa de Pós-Graduação em Saúde Coletiva da Universidade Estadual de Londrina, Paraná, Brasil. Doutora em Enfermagem pela Escola de Enfermagem de Ribeirão Preto da Universidade de São Paulo. <maragara@dilk.com.br>

\section{Referências}

ALVES, Vânia. S. Um modelo de educação em saúde para o Programa Saúde da Família: pela integralidade da atenção e reorientação do modelo assistencial. Interface - Comunicação, Saúde, Educação, Botucatu, v. 9, n. 16, p. 39-52, set. 2004/fev. 2005.

AYRES, José R. C. M. Sujeito, intersubjetividade e práticas de saúde. Ciência e Saúde Coletiva, Rio de Janeiro, v. 6, n. 1, p. 63-72, 2001.
BESEN, Candice B. et al. A Estratégia Saúde da Família como objeto de educação em saúde. Saúde e Sociedade, São Paulo, v. 16, n. 1, p. 57-68, jan./abr.2007.

BORNSTEIN, Vera J.; STOTZ, Eduardo N. O trabalho dos agentes comunitários de saúde: entre a mediação convencedora e a transformadora. Trabalho, Educação e Saúde, Rio de Janeiro, v. 6, n. 3, p. 457-480, nov.2008/fev.2009. 
BRANDÃO, Carlos R. O que é educação. São Paulo: Brasiliense, 1981.

A educação popular na área da Saúde. Interface - Comunicação, Saúde, Educação, Botucatu, v. 5, n. 8, p. 127-131, fev. 2001.

BRASIL. Ministério da Saúde. Conselho Nacional de Saúde. Resolução n ${ }^{\circ}$ 196/96, de 10 de outubro de 1996. Aprova as diretrizes e normas regulamentadoras de pesquisas envolvendo seres humanos. Brasília: Ministério da Saúde, 1996.

Ministério da Saúde. Saúde da Família: uma estratégia para a reorientação do modelo assistencial. Brasília: Ministério da Saúde, 1997.

. Ministério da Saúde. Secretaria de Atenção à Saúde. Departamento de Atenção Básica. Vigilância em saúde: dengue, esquistossomose, hanseníase, malária, tracoma e tuberculose. Brasília: Ministério da Saúde, 2007. 199 p.: il. (Série A. Normas e Manuais Técnicos - Cadernos de Atenção Básica, n. 21).

Ministério da Saúde. Secretaria Executiva. Secretaria de Gestão do Trabalho e da Educação na Saúde. Glossário temático: gestão do trabalho e da educação na saúde. Brasília: Editora do Ministério da Saúde, 2008. 56 p. (Série A. Normas e Manuais Técnicos).

BUSS, Paulo M. Uma introdução ao conceito de promoção da saúde. In: CZERESNIA, Dina (Org.). Promoção da saúde: conceitos, reflexões, tendências. 2. ed. Rio de Janeiro: Editora Fiocruz, 2009. p. 19-42.

CAMPOS, Gastão W. S. O anti-Taylor: sobre a invenção de um método para co-governar instituições de saúde produzindo liberdade e compromisso. Cadernos de Saúde Pública, Rio de Janeiro, v. 14, n. 4, p. 863-870, out./dez.1998.

CARVALHO, Yara M.; CECCIM, Ricardo B. Formação e educação em saúde: aprendizados com a Saúde Coletiva. In: CAMPOS, Gastão W. S. (Org.). Tratado de Saúde Coletiva. São Paulo: Hucitec, 2006, p. 149-182.
CECÍLIO, Luís C. O. As necessidades de saúde como conceito estruturante na luta pela integralidade e equidade na Atenção em Saúde. Rio de Janeiro: Uerj, IMS, Abrasco, 2001.

CERQUEIRA, Mariana T. Promoción de la Salud y Educación para la Salud: retos y perspectivas. In: ARROYO, Hiran V. \& CERQUEIRA, Mariana T. (Orgs.) La promoción de la salud y la educación para la salud en América Latina: un análisis sectorial. Puerto Rico, OPS/UIPES, 1997. p. 7-43.

FEUERWERKER, Laura M. Modelos tecnoassistenciais, gestão e organização do trabalho em saúde: nada é indiferente no processo de luta para a consolidação do SUS. Interface - Comunicação, Saúde, Educação, Botucatu, v. 9, n. 18, p. 489-506, set./dez. 2005.

FREIRE, Paulo. Pedagogia da autonomia: saberes necessários à prática educativa. São Paulo: Paz e Terra, 1996.

FREIRE, Paulo. Educação e mudança. 21. ed. Rio de Janeiro: Paz e Terra, 1997.

GADOTTI, Moacir. Educação e poder: introdução à pedagogia do conflito. São Paulo: Cortez; Autores Associados, 1983.

GAZZINELLI, Maria F. et al. Educação em saúde: conhecimentos, representações sociais e experiências da doença. Cadernos de Saúde Pública, Rio de Janeiro, v. 21, n. 1, p. 200-206, jan./fev. 2005.

GIL, Célia R. R. Formação de recursos humanos em Saúde da Família: paradoxos e perspectivas. Cadernos de Saúde Pública, Rio de Janeiro, v. 21, n. 2, mar./abr. 2005.

L'ABBATE, Solange. Educação em saúde: uma nova abordagem. Cadernos de Saúde Pública, Rio de Janeiro, v. 10, n. 4, p. 481490, out./dez. 1994.

LAPLANTINE, François. Antropologia da doença. São Paulo: Martins Fontes, 1991.

LUCKESI, Cipriano C. Filosofia da educação. São Paulo: Cortez, 1994. 
MATTOS, Ruben A.; PINHEIRO, Roseni (Orgs.). Os sentidos da integralidade na atenção e no cuidado à saúde. Rio de Janeiro: Uerj/IMS, 2001.

MELO, Gilberto; SANTOS, Maria R.; TREZZA Maria C.S.F. Entendimento e prática de ações educativas de profissionais do Programa Saúde da Família de São Sebastião-AL: detectando dificuldades. Revista Brasileira de Enfermagem, Brasília, v. 58, n. 3, p. 290295, maio/jun.2005.

MENDES, Eugênio V. Um novo paradigma sanitário: a produção social da saúde. In: Uma agenda para a saúde. São Paulo: Hucitec, 1996. p. 233-300.

MERHY, Emerson E. Um dos grandes desafios para gestores do SUS: apostar em novos modos de fabricar os modelos de atenção. In: MERHY, Emerson E. et al. (Orgs.) O trabalho em saúde: olhando e experienciando o SUS no cotidiano. São Paulo: Hucitec, 2003. p. 15-36.

MERHY, Emerson E.; ONOCKO, Rosana. (Orgs.). Agir em saúde: um desafio para o público. 2. ed. São Paulo: Hucitec, 1997.

MINAYO, Maria Cecília S.; DESLANDES, Suely F. Caminhos do pensamento: epistemologia e método. Rio de Janeiro: Editora Fiocruz, 2002.

MORIN, Edgar. A cabeça bem-feita: repensar a reforma, reformar o pensamento. 12. ed. Rio de Janeiro: Bertrand Brasil, 2006.

PEREIRA, Gisella. S. O profissional de saúde e a educação em saúde: representações de uma prática. 113p. Dissertação (Mestrado em Saúde e Sociedade) - Escola Nacional de Saúde Pública Sergio Arouca/Fiocruz, Rio de Janeiro, 1993.

PINAFO, Elisangela. Educação em saúde: o cotidiano da equipe de saúde da família. 131 p. Dissertação (Mestrado em Saúde Coletiva) - Universidade Estadual de Londrina, Centro de Ciências da Saúde, Programa de Pós-Graduação em Saúde Coletiva, Londrina, 2010.
RIOS, Claudia T. F; VIEIRA, Neiva. F. C. Ações educativas no pré-natal: reflexão sobre a consulta de enfermagem como espaço para a educação em saúde. Ciência \& Saúde Coletiva, Rio de Janeiro, v. 12, n. 2, p. 477486, mar./abr.2007.

SILVA, Juliana P.; ROTENBERG, Sheila; VIANNA, Eliane C. Concepção de educação em saúde na ótica dos profissionais de saúde que atuam em grupos educativos. Cadernos Saúde Coletiva, Rio de Janeiro, v. 12, n. 2, p. 119-136, 2004.

SMEKE, Elizabeth L.M.; OLIVEIRA, Nayara L.S. Educação em saúde e concepções de sujeito. In: VASCONCELOS, Eymard M. (Org.). A saúde nas palavras e nos gestos: reflexões da rede educação popular e saúde. São Paulo: Hucitec, 2001. p. 115-136.

SPINK, Mary J. (Org.). Práticas discursivas e produção de sentidos no cotidiano: aproximações teóricas e metodológicas. 3. ed. São Paulo: Cortez, 2004

VALLA, Victor V. A crise de interpretação é nossa: procurando compreender a fala das classes subalternas. Revista Educação \& Realidade, Porto Alegre, Universidade Federal do Rio Grande do Sul, v. 21, n. 2, p. 177190, 1996

VASCONCELOS, Eymard M. Educação popular nos serviços de saúde. São Paulo: Hucitec, 1997.

Educação popular nos serviços de saúde. São Paulo: Hucitec, 1999.

WENDHAUSEN, Águeda L. P.; SAUPE, Rosita. Concepções de educação em saúde e a Estratégia Saúde da Família. Texto \& Contexto Enfermagem, Florianópolis, v. 12, n. 1, p. 17-25, jan./mar.2003.

Recebido em 27/10/2010

Aprovado em 07/07/2011 